\title{
InAsSb/InPSb Strained-Layer Superlattice Growth Using Metal-Organic Chemical Vapor Deposition
}

\author{
R. M. Biefeld, J. D. Phillips, and S. R. Kurtz \\ Sandia National Laboratory, Albuquerque, NM \\ Albuquerque, NM 87185-0601
}

\begin{abstract}
OSTI

We report on the metal-organic chemical vapor deposition (MOCVD) of strained layer superlattices (SLSs) of InAsSb/InPSb as well as mid-infrared optically pumped lasers grown using a high speed rotating disk reactor (RDR). The devices contain AlAsSb cladding layers and strained, type I, InAsSb/InPSb active regions. By changing the layer thickness and composition of InAsSb/InPSb SLSs, we have prepared structures with low temperature $(<20 \mathrm{~K})$ photoluminescence wavelengths ranging from 3.4 to $4.8 \mu \mathrm{m}$. We find a variation in bandgap of 0.272 to $0.324 \mathrm{eV}$ for layer thicknesses of 9.0 to $18.2 \mathrm{~nm}$. From these data we have estimated a valence band offset for the InAsSb/InPSb interface of about $400 \mathrm{meV}$. The optical properties of the superlattices revealed an anomalous low energy transition that can be assigned to an antimony rich interfacial layer in the superlattice. An InAsSb/InPSb SLS, laser was grown on an InAs substrate with $\mathrm{AlAs}_{0.16} \mathrm{Sb}_{0.84}$ cladding layers. A lasing threshold and spectrally narrowed laser emission were seen from 80 through $200 \mathrm{~K}$, the maximum temperature where lasing occurred. The temperature dependence of the SLS laser threshold is described by a characteristic temperature, $\mathrm{T}_{0}=72 \mathrm{~K}$, from 80 to $200 \mathrm{~K}$.
\end{abstract}

RECEIVED

AUG 241099 


\section{DISCLAIMER}

This report was prepared as an account of work sponsored by an agency of the United States Government. Neither the United States Government nor any agency thereof, nor any of their employees, make any warranty, express or implied, or assumes any legal liability or responsibility for the accuracy, completeness, or usefulness of any information, apparatus, product, or process disclosed, or represents that its use would not infringe privately owned rights. Reference herein to any specific commercial product, process, or service by trade name, trademark, manufacturer, or otherwise does not necessarily constitute or imply its endorsement, recommendation, or favoring by the United States Government or any agency thereof. The views and opinions of authors expressed herein do not necessarily state or reflect those of the United States Government or any agency thereof. 


\section{DISCLAIMER}

Portions of this document may be illegible in electronic image products. Images are produced from the best available original document. 


\section{Introduction}

We are exploring the growth of novel mid-infrared $(3-5 \mu \mathrm{m})$ emitters (lasers and LED's) by metal-organic chemical vapor deposition (MOCVD) for use in infrared countermeasures and chemical sensor systems. Previously we have made gain-guided, injection lasers using not intentionally doped, p-type $\mathrm{AlAs}_{0.16} \mathrm{Sb}_{0.84}$ for optical confinement and both strained InAsSb/InAs multiple quantum well (MQW) and InAsSb/InAsP strained-layer superlattice (SLS) active regions [1,2]. We have also: reported the first ten-stage cascaded lasers and LED's with type I InAsSb/InAsP quantum-well active regions grown by MOCVD [3]. These cascaded lasers employ a (p) $\mathrm{GaAsSb} /(\mathrm{n})$ InAs semimetal electron/hole source between stages. In compressively strained InAsSb SLSs, it is necessary to maximize the light-heavy $(13 / 2, \pm 1 / 2>$ $13 / 2, \pm 3 / 2>$ ) hole splitting to suppress non-radiative Auger recombination. Recently, Bewley et al. have reported record high output powers and operating temperatures for mid-infrared InAs/GaInSb/AlAsSb type II optically pumped lasers using a diamondpressure-bond heat sinking technique [4]. We are currently exploring the growth of new emitter structures as well as the use of novel materials in these structures to improve our laser performance. In an attempt to further reduce the Auger recombination by increasing the hole confinement, we have used InPSb in place of InAsP as the barrier layer in the active region. We report on the synthesis and properties of these InAsSb/InPSb SLSs grown by MOCVD and their use in 3-4 $\mu \mathrm{m}$, mid-infrared optoelectronic heterojunction emitters. 


\section{Experimental}

The InAsSb/InPSb SLSs were grown by MOCVD on undoped n-type InAs substrates. We optimized the growth of these structures by first investigating the growth of InAsSb/InAs and InPSb/InAs strained layer superlattices (SLSs). We investigated different purge times $(1,3$, and 5) seconds with and without arsine flowing during the purge between InAs and the ternary layer growth to determine the effect of the purge on the quality of the photoluminescence for the SLSs. A low V/III ratio is necessary for the growth of high quality InAsSb due to the low vapor pressure of $\mathrm{Sb}$; excess $\mathrm{Sb}$ tends to cause surface morphology defects. For InPSb, the V/mI ratio is dominated by the excess phosphine flow. The high $\mathrm{V} / \mathrm{II}$ ratio and excess phosphine flow are necessary because of the high decomposition temperature of phosphine. In both cases, InAsSb/InAs and InPSb/InAs, the composition dependence was reproducible and approximately linear versus $\mathrm{AsH}_{3}$ flow for InAsSb and TESb flow for InPSb for the composition range that was examined.

The SLSs were grown at 500 or $550^{\circ} \mathrm{C}$ and 70 torr in an Emcore D75 high speed rotating disk reactor at $1100 \mathrm{rpm}$. The sources used were trimethylindium (TMIn), triethylantimony (TESb), $100 \%$ or $10 \% \mathrm{AsH}_{3}$ in hydrogen, and $100 \% \mathrm{PH}_{3}$. The carrier gas and its quantity were 15 liters of hydrogen. The SLS composition and strain were determined by double crystal x-ray diffraction (DCXRD).

Infrared photoluminescence (PL) was measured on all samples from $16 \mathrm{~K}$ up to $300 \mathrm{~K}$ using a double-modulation, Fourier-transform infrared (FTIR) technique which provides high sensitivity, reduces sample heating, and eliminates the 
blackbody background from infrared emission spectra. The laser output characteristics were also measured using double modulation FTIR.

\section{Results and Discussion}

The InAsSb layers were grown using a V/III ratio of 7.5 to 15 and an $\mathrm{AsH}_{3} /\left(\mathrm{AsH}_{3}+\mathrm{TESb}\right)$ ratio of 0.69 to 0.88 for compositions between 0.1 and $0.25 \mathrm{Sb}$ in InAsSb at a growth rate between 2.5 to $5 \AA$ /second. For the laser structures, a 1 second purge, with all reactants except for $\mathrm{AsH}_{3}$ switched out of the chamber, was used between each layer. This was the procedure that had been used previously for the growth of InAsSb/AnAsP laser structures [2]. The growth rate was found to be proportional to the TMIn flow into the reaction chamber and independent of the TESb and AsH3 flow. The InPSb layers, whose growth has been described in more detail previously [5], were grown using a V/III ratio of between 400 to 900 and a TESb/(TESb $\left.+\mathrm{PH}_{3}\right)$ ratio of 0.004 to 0.002 with growth rates of 2.5 to $5 \AA /$ second for compositions between 0.8 and $0.7 \mathrm{P}$ in InPSb. If the TESb/(TESb $\left.+\mathrm{PH}_{3}\right)$ ratio was decreased below 0.002 , poor quality superlattices resulted. The SLS composition and strain were determined by double crystal $\mathrm{x}$-ray diffraction. The crystal quality of the SLSs was excellent with 4 to 5 orders of $\mathrm{x}$ ray diffraction satellite peaks typically observed, with typical full width at half maximum linewidths of $80-100 \mathrm{arcsec}$. The variation of the $\mathrm{Sb}$ composition for the InAsSb layer, as determined by DCXRD, from 0.115 to 0.18 as a function of $\mathrm{AsH}_{3}$ flow for a fixed TESb flow is shown in Figure 1. Under similar conditions, the $\mathrm{Sb}$ composition could be varied between 0.13 to 0.24 while maintaining constant layer thickness for both the InAsSb and InPSb layers. 
The PL peak wavelength dependence on composition for the SLSs is shown in Figure 2. For a change of composition in $\operatorname{InAs}_{1-\mathrm{x}} \mathrm{Sb}_{\mathrm{x}}$, for $\mathrm{x}=0.14$ to 0.20 , with InP $\mathrm{P}_{0.72-0.75} \mathrm{Sb}_{0.28-0.25}$ barriers, the PL peak changes from 3.5 to $4.2 \mu \mathrm{m}$ at $16 \mathrm{~K}$ and a corresponding shift to longer wavelengths is observed at room temperature.

Photoluminescence linewidths (full width at half maximum) of $\sim 15 \mathrm{meV}$ and $\sim 35 \mathrm{meV}$ are typically observed at $16 \mathrm{~K}$ and room temperature, respectively, with no observable dependence on antimony composition. A decrease in the PL peak intensity by an order of magnitude is observed for samples with $\operatorname{InAs}_{I-x} \mathrm{Sb}_{\mathrm{x}}, \mathrm{x}<0.16$, likely due to decreased carrier confinement. By changing the layer thickness and composition of InAsSb/InPSb SLSs, we have prepared structures with low temperature $(<20 \mathrm{~K})$ photoluminescence wavelengths ranging from 3.4 to $4.8 \mu \mathrm{m}$. Initial quantum confinement data (Figure 3) from samples of varying InAs ${ }_{0.81} \mathrm{Sb}_{0.19}$ thickness indicate that there is about a factor of two greater valence band offset between $\operatorname{InP}_{0.75} \mathrm{Sb}_{0.25}$ and $\operatorname{InAs} \mathrm{s}_{0.81} \mathrm{Sb}_{0.19}$ than between In $\mathrm{As}_{0.65} \mathrm{P}_{0.35}$ and $\operatorname{InAs} \mathrm{s}_{0.81} \mathrm{Sb}_{0.19}$. Figure 3 illustrates the variation of bandgap from 0.272 to $0.324 \mathrm{eV}$ for layer thicknesses of 9.0 to $18.2 \mathrm{~nm}$. The bandgap of non-ordered $\operatorname{InP}_{0.75} \mathrm{Sb}_{0.25}$ is estimated to be approximately $0.8 \mathrm{eV}$ [5]. From these data we have estimated a valence band offset for the $\operatorname{InP}_{0.75} \mathrm{Sb}_{0.25}$ and InAs $\mathrm{s}_{0.81} \mathrm{Sb}_{0.19}$ interface of about $0.4 \mathrm{eV}$

We have also observed a long wavelength emission in the photoluminescence that was not attributable to the InAsSb. Figure 4 shows the 16 and $300 \mathrm{~K} \mathrm{PL}$ spectra of an InAs $0.84 \mathrm{Sb}_{0.15} / \operatorname{InP}_{0.75} \mathrm{Sb}_{0.25} 10$ period SLS grown at $500{ }^{\circ} \mathrm{C}$. Peaks from the InAs substrate $(3.0$ and $3.25 \mu \mathrm{m})$, the InAsSb layer $(3.65 \mu \mathrm{m})$ and a longer emission at $4.5 \mu \mathrm{m}$ are observed in the $16 \mathrm{~K}$ spectrum; however, at $300 \mathrm{~K}$ the long wavelength peak 
disappears. This anomalous long wavelength peak could be reduced by growing at 550 ${ }^{0} \mathrm{C}$ and by increasing the Sb content of the InAsSb layer. Figure 5 illustrates the PL peaks that are observed for an InAs / InP ${ }_{0.75} \mathrm{Sb}_{0.25} 10$ period SLS. We would expect only the PL peaks from InAs and the shorter wavelength emission from InPSb, but we again observed the anomalous long wavelength peak near $5 \mu \mathrm{m}$. As illustrated in Figure 5, we have found that this anomalous peak can be effectively eliminated by increasing the $\mathrm{AsH}_{3}$ exposure of the InPSb/InAs interfaces. Figure 5 shows the PL spectra from three InPSb/InAs SLSs grown with different exposure levels of $\mathrm{AsH}_{3}$ ranging from a 1 second purge in which no $\mathrm{AsH}_{3}$ was used in Figure 5a-to 3 and 5 second purges with $\mathrm{AsH}_{3}$ flowing during the purges shown in Figures $5 \mathrm{~b}$ and $\mathrm{c}$, respectively. From this result we conclude that the anomalous long wavelength PL peak is due to an interfacial layer that can be minimized by changing the growth conditions at the interface.

An optically pumped heterostructure laser was grown on an InAs substrate with a $2 \mu \mathrm{m}$ thick $\mathrm{AlAs}_{0.16} \mathrm{Sb}_{0.84}$ lower cladding followed by a $0.5 \mu \mathrm{m}$ InAs spacer. On top of the InAs spacer, the active region consisted of a 10 period, $\operatorname{InAs} \mathrm{As}_{0.82} \mathrm{Sb}_{0.18} / \mathrm{InP}_{0.73} \mathrm{Sb}_{0.27}(104$ $\AA / 104 \AA$ ) SLS. In this particular structure, the TESb flows were graded between 80 and $250 \mathrm{sccm}$ over the first 20 percent of both layers growth time to maintain a high TESb concentration at the interface and to increase the $\mathrm{P}$ in the barrier layer. The lower TESb flow was used in the InPSb layer. An increase in the P in the barrier layer was confirmed by a shift in the $\mathrm{x}$-ray diffraction pattern of greater than 100 arc seconds relative to samples without changing TESb flows during growth. This grading scheme undoubtedly also resulted in a graded interface between the superlattice layers. The structure was then completed with another $0.5 \mu \mathrm{m}$ of InAs and a $1.0 \mu \mathrm{m}$ top $\mathrm{AlAs}_{0.16} \mathrm{Sb}_{0.84}$ cladding layer. 
The $\mathrm{AlAs}_{0.16} \mathrm{Sb}_{0.84}$ cladding layer was covered with a $40 \mathrm{~nm}$ InAs cap layer to avoid oxidation. Laser devices were fabricated by cleaving the grown heterostructures into $1 \mathrm{x}$ $5 \mathrm{~mm}$ bars, with uncoated facets, and mounting them on a copper heat sink using In solder. The SLS laser was pumped with a Q-switched Nd:YAG laser $(1.06 \mu \mathrm{m}, 20 \mathrm{~Hz}$, 10 nsec pulse, focused to a $200 \mu \mathrm{m}$ wide line), and emission was detected with an FTIR spectrometer operated in a step-scan mode. A lasing threshold and spectrally narrowed, laser emission were seen from 80 through $240 \mathrm{~K}$, the maximum temperature where lasing occurred. The wavelength of our laser did not appear to shift from $4.00 \mu \mathrm{m}$ over the 140 $200 \mathrm{~K}$ temperature range, however we see a significant luminescence contribution near 3.2 $\mu \mathrm{m}$ from the InAs spacers. The photoluminescence peak energy for this structure shifted from 3.93 to $4.54 \mu \mathrm{m}$ over a temperature range of 16 to $300 \mathrm{~K}$. For this InAsSb/InPSb SLS laser, emission occurred nearer to peak of the PL emission than previously reported for MOCVD-grown devices with pseudomorphic InAsSb MQW active regions [1]. The temperature dependence of the SLS laser threshold is described by a characteristic temperature, $T_{0}=72 \mathrm{~K}$, from 80 to $200 \mathrm{~K}$. This value is higher than observed in our previous lasers [1-3], and suggests that the use of InPSb barriers will lead to increased operating temperatures compared to the lasers with InAsP barriers. This higher characteristic temperature is similar to those observed in the current state of the art InAs/GaInSb/AlAsSb type II optically pumped lasers [4]. Above $200 \mathrm{~K}$, luminescence from the InAs spacers becomes dominant, and a corresponding sharp decrease in $T_{0}$ is observed. At $70-130 \mathrm{~K}$, the estimated peak powers and thresholds of about $250-10$ $\mathrm{mW} /$ facet and $10-100 \mathrm{~kW} / \mathrm{cm}^{2}$ are similar to those observed for the previously reported InAsSb/InAsP SLS lasers [2]. 
In summary, we have successfully prepared InAsSb/InPSb SLSs by MOCVD. We observed a long wavelength emission which we have assigned to an interface state by examining the PL of InAs/InPSb SLSs. We have prepared optically pumped laser structures using InAsSb/InPSb SLSs as the active regions and observed a record high $\mathrm{T}_{0}$ for these type I InAsSb SLS lasers. With further improvement in growth conditions optimization of the interface transition, and laser design, the high $\mathrm{T}_{0}$ we have observed leads us to believe that higher performance lasers are possible with the InAsSb/InPSb SLSs.

Acknowledgements

*This work was supported by the US DOE under Contract No. DE-AC04-94AL85000. Sandia is a multiprogram laboratory operated by Sandia Corporation, a Lockheed Martin Company, for the United States Department of Energy.

\section{References}

[1] A. A. Allerman, R. M. Biefeld, and S. R.Kurtz, "InAsSb-based mid-infrared lasers (3.8-3.9 $\mu \mathrm{m})$ and light-emitting diodes with AlAsSb claddings and semi-metal electron injection grown by metal-organic chemical vapor deposition," Appl. Phys. Lett. 69, pp. 465-467, 1996. 
[2] S. R. Kurtz, A. A. Allerman, and R. M. Biefeld "Mid-infrared lasers and lightemitting diodes with InAsSb/InAsP strained-layer superlattice active regions" Appl. Phys. Lett. 70, pp. 3188-3190, 1997.

[3] S. R. Kurtz, A. A. Allerman, R. M. Biefeld and K. C. Baucom, "High slope efficiency, "cascaded" midinfrared lasers with type I InAsSb quantum wells" Appl. Phys. Lett. 72, pp. 2093-2095, 1998.

[4] W. W. Bewley, C. L. Felix, I. Vurgaftman, D. W. Stokes, E. H. Aifer, L. J. Olafsen, J. R. Meyer, M. J. Yang, B. V. Shanabrook, H. Lee, R. U. Martinelli, and A. R. Sugg "High-temperature continuous-wave 3-6.1 m "W" lasers with diamond-pressure-bond heat sinking" Appl. Phys. Lett. 74, 1075 (1999).

[5] R. M. Biefeld, K. C. Baucom, S. R. Kurtz, and D. M. Follstaedt, "The growth of $\operatorname{InP}_{1-}$ ${ }_{x} \mathrm{Sb}_{\mathrm{x}}$ by metalorganic chemical vapor deposition", J. Crystal Growth 133, 38 (1993). 


\section{Figure Captions}

Figure 1. Incorporation of $\mathrm{Sb}$ into the InAsSb layer as a function of $\mathrm{AsH}_{3} /\left(\mathrm{AsH}_{3}+\right.$ TESb)ratio in the vapor phase for the InAsSb/InPSb SLSs.

Figure 2. Low temperature PL $(<20 \mathrm{~K})$ from 10 period $108 \AA \mathrm{InSb}_{\mathrm{x}} \mathrm{As}_{\mathrm{I}-\mathrm{x}} / 108 \AA$ $\mathrm{InP}_{0.74} \mathrm{Sb}_{0.26} \mathrm{SLS}$ 's grown on InAs for different $\mathrm{Sb}$ content in the InAsSb layer.

Figure3. Bandgap versus InAsSb layer thicknesses in InAsSb/InPSb SLSs, taken from PL data at $16 \mathrm{~K}$, showing the effects of quantum confinement.

Figure 4. The 16 and $300 \mathrm{~K}$ PL spectra in (a) and (b), respectively, of an InAs ${ }_{0.84} \mathrm{Sb}_{0.15} /$ $\operatorname{InP}_{0.75} \mathrm{Sb}_{0.25} 10$ period SLS grown at $500^{\circ} \mathrm{C}$.

Figure 5. The PL spectra from three InPSb/InAs SLSs grown with different exposure levels of $\mathrm{AsH}_{3}$ ranging from (a) 1 second purge in which no $\mathrm{AsH}_{3}$ was used to 3 and 5 second purges with $\mathrm{AsH}_{3}$ flowing during the purges shown in Figures $5 \mathrm{~b}$ and $\mathrm{c}$, respectively. 
Figures For

InAsSb/InPSb Strained-Layer Superlattice Growth Using

Metal-Organic Chemical Vapor Deposition

R. M. Biefeld, J. D. Phillips, and S. R. Kurtz

Sandia National Laboratories*

Albuquerque, NM 87185-0601 


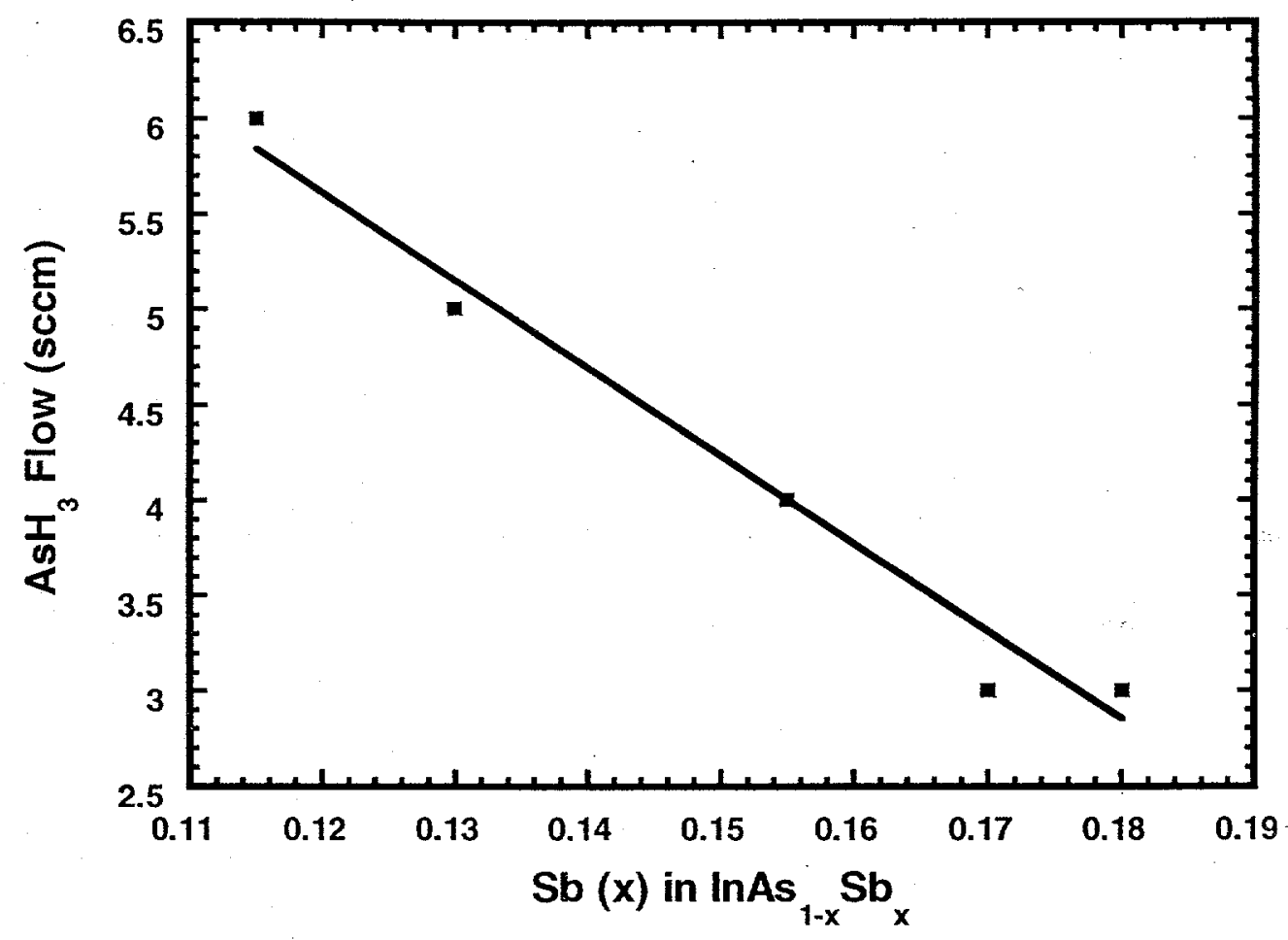

Figure 1. Incorporation of $\mathrm{Sb}$ into the InAsSb layer as a function of $\mathrm{AsH}_{3} / \mathrm{AsH}_{3}+$ $\mathrm{TESb}$ )ratio in the vapor phase for the InAsSb/InPSb SLSs. 


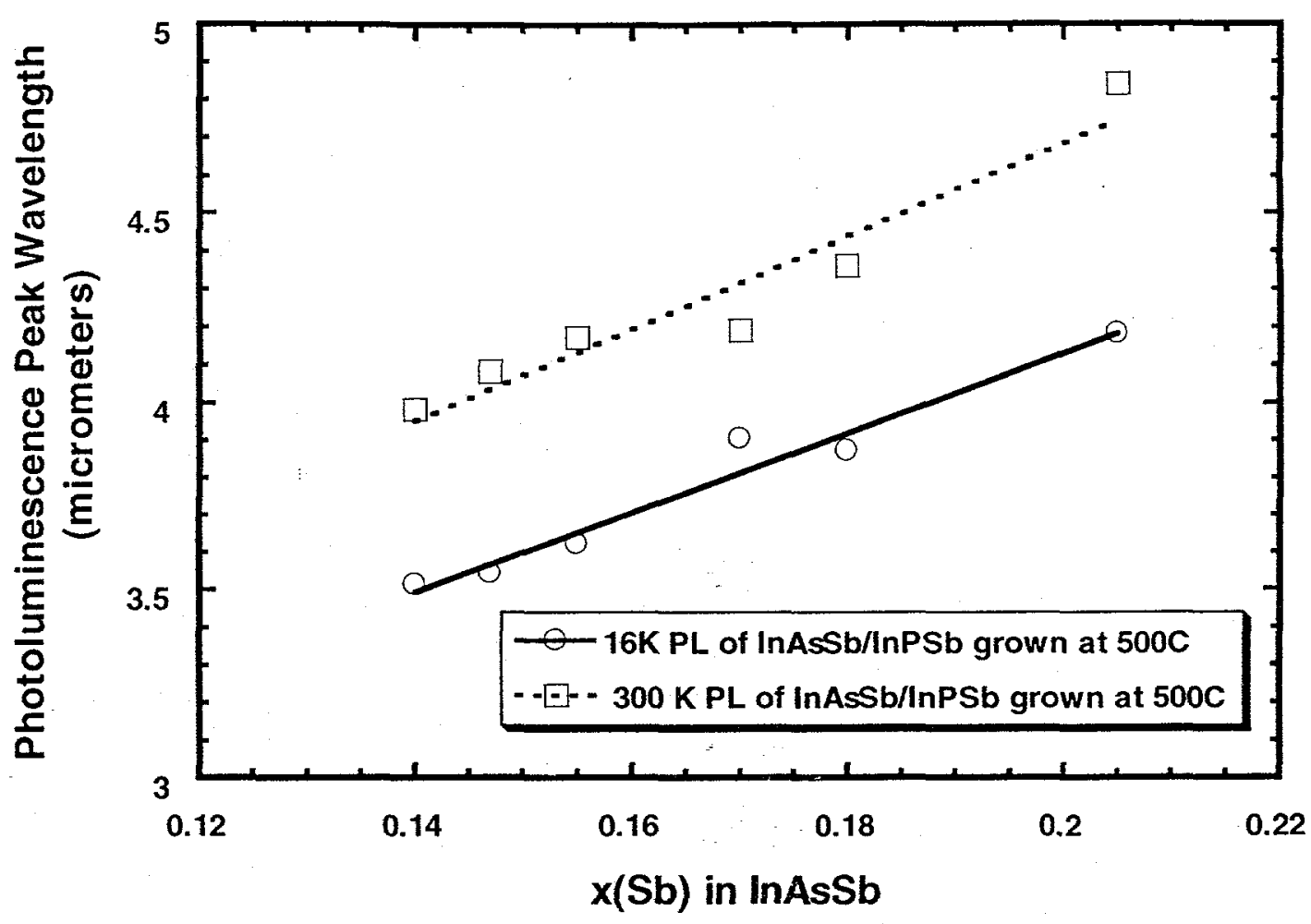

Figure 2. Low temperature PL $\left(<20 \mathrm{~K}\right.$ ) from 10 period $108 \AA \operatorname{lnSb}_{\mathrm{x}} \mathrm{As}_{1-\mathrm{x}} / 108 \AA$ InP $\mathrm{P}_{0.74} \mathrm{Sb}_{0.26}$ SLS's grown on InAs for different $\mathrm{Sb}$ content in the InAsSb layer. 


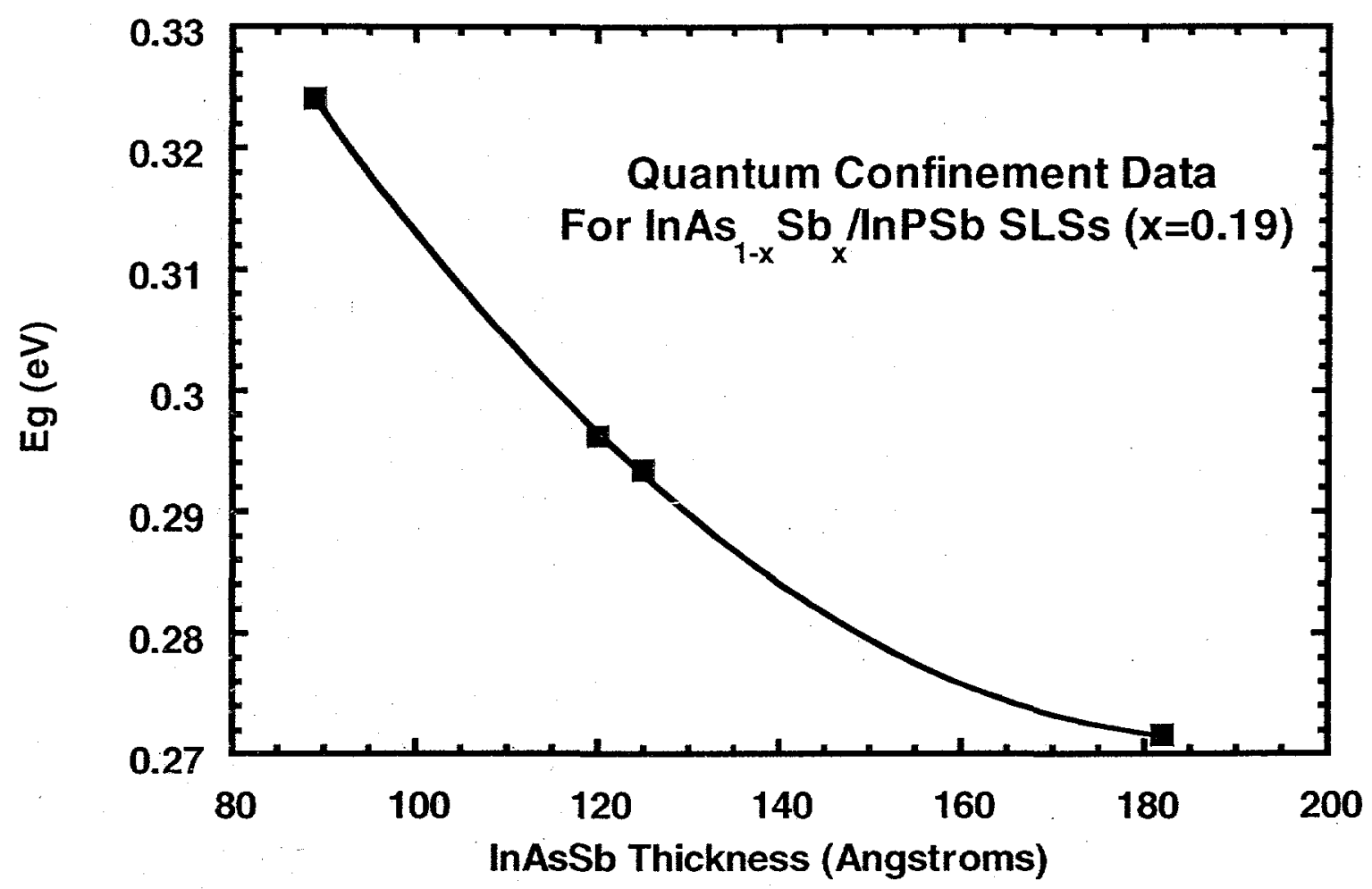

Figure3. Bandgap versus InAsSb layer thicknesses in InAsSb/InPSb SLSs, taken from PL data at $16 \mathrm{~K}$, showing the effects of quantum confinement. 

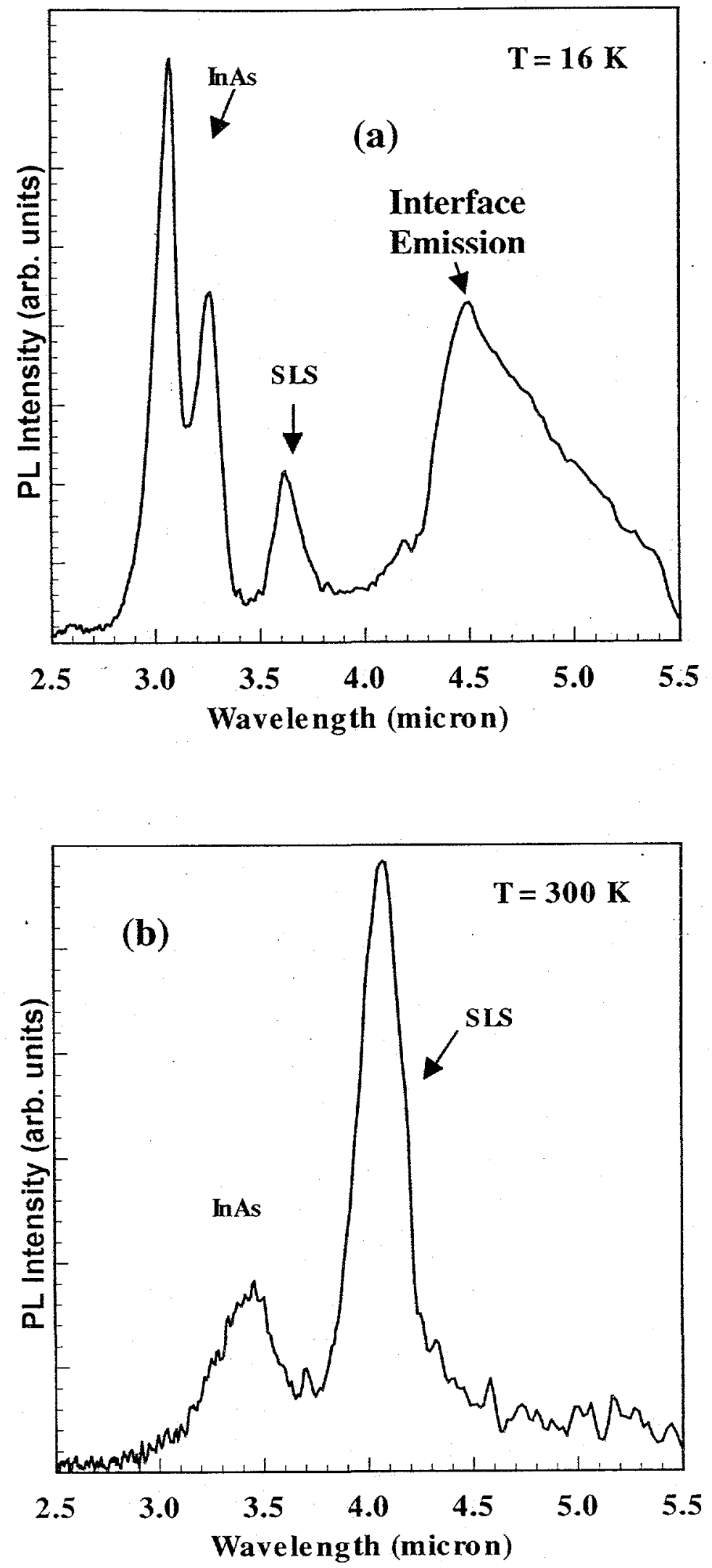

Figure 4. The 16 and $300 \mathrm{~K}$ PL spectra in (a) and (b), respectively, of an InAs $\mathrm{s}_{0.84} \mathrm{Sb}_{0.15} /$ InP $\mathrm{P}_{0.75} \mathrm{Sb}_{0.25} 10$ period SLS grown at $500^{\circ} \mathrm{C}$. 


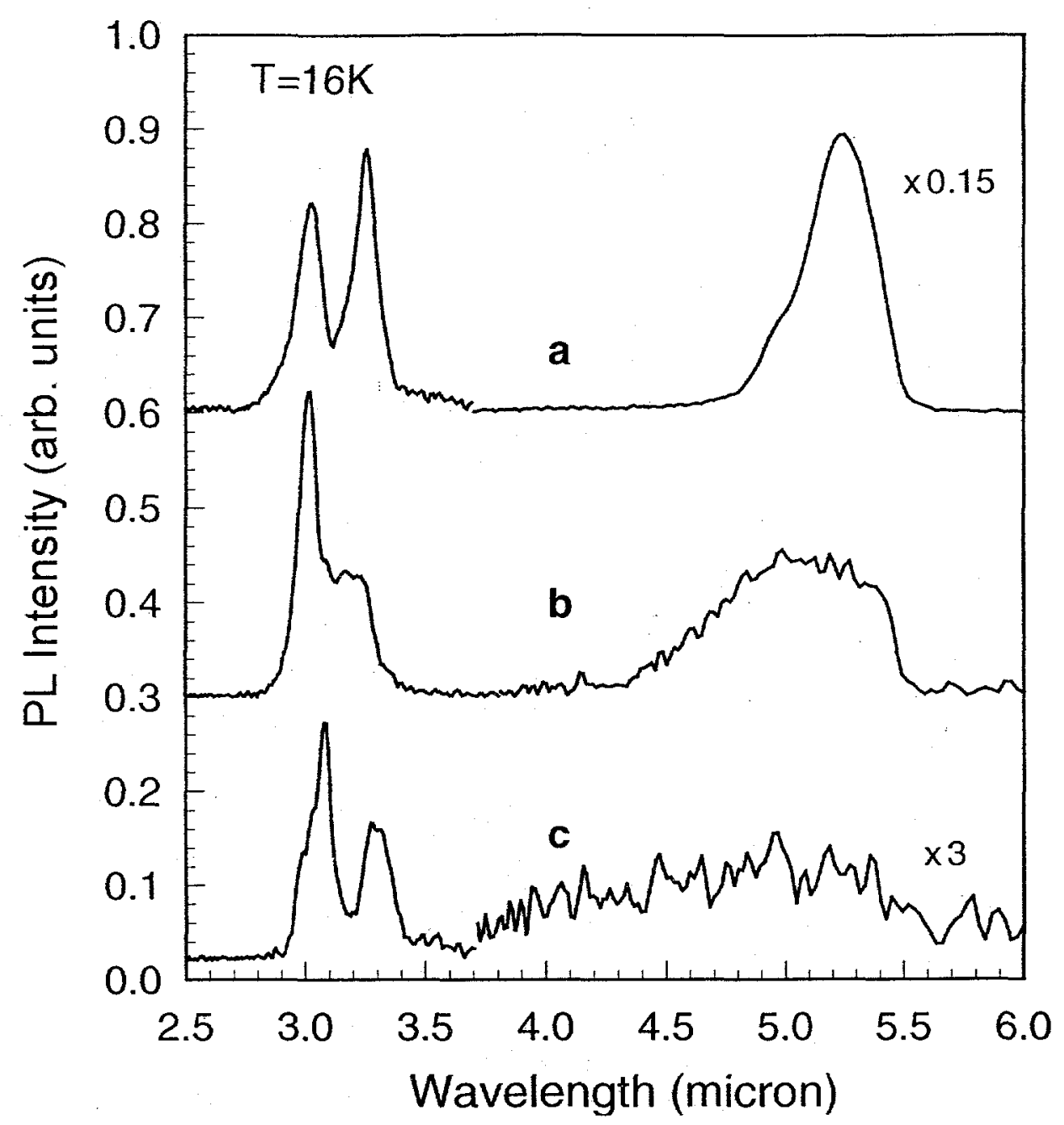

Figure 5. The PL spectra from three InPSb/InAs SLSs grown with different exposure levels of $\mathrm{AsH}_{3}$ ranging from (a) 1 second purge in which no $\mathrm{AsH}_{3}$ was used to 3 and 5 second purges with $\mathrm{AsH}_{3}$ flowing during the purges shown in Figures $5 \mathrm{~b}$ and $\mathrm{c}$, respectively. 